\title{
Age-Related Changes in Expression and Activity of Human Hepatic Mitochondrial Glutathione Transferase Zeta1 ${ }^{\text {丽 }}$
}

\author{
Guo Zhong, Margaret O. James, Marci G. Smeltz, Stephan C. Jahn, Taimour Langaee, \\ Pippa Simpson, and Peter W. Stacpoole
}

\begin{abstract}
Department of Medicinal Chemistry (G.Z., M.O.J., M.G.S., S.C.J.), Department of Pharmacotherapy and Translational Research (T.L.), Center for Pharmacogenomics (T.L.), and Departments of Medicine and Biochemistry and Molecular Biology (P.W.S.), University of Florida, Gainesville, Florida; and Department of Pediatrics, Medical College of Wisconsin, Milwaukee, Wisconsin (P.S.)
\end{abstract}

Received April 2, 2018; accepted May 29, 2018

\begin{abstract}
Glutathione transferase zeta1 (GSTZ1) catalyzes glutathione (GSH)dependent dechlorination of dichloroacetate (DCA), an investigational drug with therapeutic potential in metabolic disorders and cancer. GSTZ1 is expressed in both hepatic cytosol and mitochondria. Here, we examined the ontogeny and characterized the properties of human mitochondrial GSTZ1. GSTZ1 expression and activity with DCA were determined in 103 human hepatic mitochondrial samples prepared from livers of donors aged 1 day to 84 years. DNA from each sample was genotyped for three common GSTZ1 functional single nucleotide polymorphisms. Expression of mitochondrial GSTZ1 protein increased in an age-dependent manner to a plateau after age 21 years. Activity with DCA correlated with expression, after taking into account the somewhat higher activity of samples that were homo- or heterozygous for GSTZ1A. In
\end{abstract}

samples from livers with the GSTZ1C variant, apparent enzyme kinetic constants for DCA and GSH were similar for mitochondria and cytosol after correcting for the loss of GSH observed in mitochondrial incubations. In the presence of $38 \mathrm{mM}$ chloride, mitochondrial GSTZ1 exhibited shorter half-lives of inactivation compared with the cytosolic enzyme $(P=0.017)$. GSTZ1 protein isolated from mitochondria was shown by mass spectrometry to be identical to cytosolic GSTZ1 protein in the covered primary protein sequence. In summary, we report age-related development in the expression and activity of human hepatic mitochondrial GSTZ1 does not have the same pattern as that reported for cytosolic GSTZ1. Some properties of cytosolic and mitochondrial GSTZ1 differed, but these were not related to differences in amino acid sequence or post-translationally modified residues.

\section{Introduction}

Glutathione transferase zeta1 (GSTZ1), also known as maleylacetoacetate isomerase, catalyzes the isomerization of maleylacetoacetate to fumarylacetoacetate, one of the reactions involved in the process of tyrosine degradation (Board and Anders, 2011). GSTZ1 is also responsible for biotransformation of $\alpha$-haloacetic acids (Tong et al., 1998). Dichloroacetate (DCA) is converted to an inactive metabolite, glyoxylate, through glutathione (GSH)-dependent dechlorination by

Portions of this work were included in Guo Zhong's Ph.D. dissertation, "Human Liver Glutathione Transferase Zeta1 (GSTZ1) in Mitochondria and Dichloroacetate-Induced GSTZ1 Inactivation, Roles of Anions, Age and Subcellular Location," located at the University of Florida Digital Collections. A preliminary report of this work was presented in September 2014 at the national meeting of the International Society for the Study of Xenobiotics.

This work was funded in part by grants from the U.S. Public Health Service [Grant R01 GM 099871]; the Brain and Tissue Bank for Developmental Disorders, University of Maryland, Baltimore, MD, and University of Miami, Coral Gables, FL [Grant NO1 HD90011]; the National Cancer Institute Cooperative Human Tissue Network; and the National Institutes of Health National Center for Advancing Translational Sciences Clinical and Translational Science award to the University of Florida [Award UL1 TR000064]

https://doi.org/10.1124/dmd.118.081810.

S This article has supplemental material available at dmd.aspetjournals.org.
GSTZ1 (James et al., 1997). DCA is an investigational drug with potential clinical applications in treating cancer and cardiovascular and metabolic disorders (Stacpoole, 2011; Kankotia and Stacpoole, 2014; James et al., 2017). Its primary mechanism of action is to inhibit mitochondrial pyruvate dehydrogenase kinase, thereby maintaining the pyruvate dehydrogenase complex in its unphosphorylated, catalytically active form (Stacpoole et al., 1998). The pyruvate dehydrogenase complex functions as a key cellular homeostat in regulating mitochondrial fuel metabolism and oxidative phosphorylation. Repeated dosing of DCA causes slower clearance of the drug in both human and animals, resulting from the inactivation of GSTZ1 (James et al., 1998; Tzeng et al., 2000; Shroads et al., 2008). Inactivation of GSTZ1 leads to accumulation of DCA as well as the chemically reactive tyrosine catabolites maleylacetoacetate and maleylacetone (Lantum et al., 2003; Shroads et al., 2008), which are possibly related to DCA's toxicity since they are known to form adducts (Lantum et al., 2002b). A better understanding of DCA metabolism is important in selecting appropriate doses for patients.

Several factors have been demonstrated to influence DCA metabolism, including GSTZ1 haplotype, age, and liver chloride concentration. In the coding region of the human GSTZ1 gene there are three common nonsynonymous functional single nucleotide polymorphisms (SNPs): rs7975 G > A (E32K); rs7972 G > A (G42R); and rs1046428 C > T (T82M). In populations studied to date, these SNPs result in five major

ABBREVIATIONS: ABC, ammonium bicarbonate; ACN, acetonitrile; DCA, dichloroacetate; GGT, $\gamma$-glutamyl transpeptidase; Gln, glutamine; GSH, glutathione; GSTZ1, glutathione transferase zeta1; MS/MS, tandem mass spectrometry; NaDCA, sodium dichloroacetate; SNP, single nucleotide polymorphism; $t_{1 / 2}$, inactivation half-life. 
haplotypes, as reviewed recently in James and Stacpoole (2016). In order of frequency in populations studied to date these are EGT (GSTZ1C, most common, 45\%-55\%); KGT (GSTZ1B, 25\%-35\%); EGM (GSTZ1D, 10\%-20\%); KRT (GSTZ1A, 1\%-10\%); and KGM (GSTZ1F, 0\%-2\%). In vitro studies examining GSTZ1 activity with DCA in human liver cytosol showed that activity in cytosols from GSTZ1A carriers was about 3-fold higher than in those from livers carrying all the other variants (non-GSTZ1A carriers), although when samples from all ethnicities were compared the expression levels of GSTZ1 protein among the variants were similar (Li et al., 2012). Other variants have been reported, but are very rare (Yang et al., 2017). In people, age affects DCA pharmacokinetics and toxicity. Chronic treatment with DCA results in a greater decrease in drug clearance in adults compared with children (Shroads et al., 2008). Adults are also more susceptible than children to peripheral neuropathy, the principal adverse side effect caused by chronic DCA treatment (Kaufmann et al., 2006; Stacpoole et al., 2008). Chloride, at a concentration of $38 \mathrm{mM}$, which is reported to be the mean concentration in four human liver samples (Widdowson and Dickerson, 1960), substantially extended half-lives of DCA-induced GSTZ1 inactivation in human liver cytosol samples through an as yet unknown mechanism (Zhong et al., 2014). The concentration of chloride that protected cytosolic GSTZ1 from inactivation was haplotype dependent (Zhong et al., 2014). Further studies of the chloride concentration of human liver in 97 donors aged 1 day to 84 years showed the mean whole liver concentration was $42 \mathrm{mM}$ and the chloride concentration in human liver cytosol averaged $105 \mathrm{mM}$ and exhibited an age-related decline, while mitochondrial chloride concentrations were lower $(4.2 \mathrm{mM})$ and increased slightly with age (Jahn et al., 2015).

GSTZ1 mRNA expression in humans was highest in liver among all tested tissues (Uhlén et al., 2015). Based on studies in rodents, hepatic cytosol is the major protein expression site of GSTZ1 (Lantum et al., 2002a; Jahn et al., 2018). Aside from cytosol, GSTZ1 was expressed in the hepatic mitochondrial matrix in both humans and rats, but at a lower level compared with cytosol (Li et al., 2011). Previously, the ontogeny of human hepatic cytosolic GSTZ1 was studied in our laboratory (Li et al., 2012). Since the mechanism for mitochondrial incorporation of the enzyme is not clear, it is not known if GSTZ1 expressed in human liver mitochondria exhibits identical properties to the cytosolic form with respect to ontogeny, enzyme kinetics, primary protein sequence, and DCA-induced inactivation. Considering that the mitochondrion is the primary action site of DCA, and the further metabolism of glyoxylate to carbon dioxide and glycine takes place there, mitochondria play an important role in DCA biotransformation (James et al., 1998). A deeper understanding of mitochondrial GSTZ1 properties will improve our understanding of the fate of DCA in people (James et al., 2017). In this study, we investigated the developmental pattern of human GSTZ1 in liver mitochondria. We also tested the hypothesis that mitochondrial GSTZ1 differs from cytosolic GSTZ1 in enzyme kinetics and stability properties related to DCA-induced inactivation.

\section{Methods and Materials}

Chemicals and Reagents. An aqueous $2 \mathrm{mM}$ solution of $\mathrm{Na}\left[1-{ }^{14} \mathrm{C}\right]-$ DCA containing $10-40 \mu \mathrm{Ci} / \mathrm{ml}$ was made by neutralizing $\left[1-{ }^{14} \mathrm{C}\right]-\mathrm{DCA}$ (56 $\mathrm{mCi} / \mathrm{mmol}, 99 \%$ purity), purchased from American Radiolabeled Chemicals (St. Louis, MO), with $\mathrm{NaHCO}_{3}$ and then adding unlabeled clinical grade sodium DCA (NaDCA) (TCI America, Portland, OR) to the desired concentration and specific activity. All other chemicals and reagents used in this study were of American Chemical Society grade or higher and were purchased from commercial suppliers.
Human Liver Samples. Normal human liver samples from 41 female and 62 male de-identified donors, aged 1 day to 84 years, were obtained from three tissue banks under an exempt protocol reviewed and approved by the University of Florida Internal Review Board. The tissue banks were the Cooperative Human Tissue Network (University of Alabama at Birmingham, Birmingham, AL), the NICHD Brain and Tissue Bank (University of Maryland, Baltimore, MD), and the University of Florida Clinical and Translational Science Institute. Samples were processed into subcellular fractions following published procedures (Li et al., 2011) and stored at $-80^{\circ} \mathrm{C}$ until use. DNA was isolated from nuclear pellets for genotyping: following amplification by polymerase chain reaction, hepatic DNA was pyrosequenced, targeting the three common nonsynonymous SNPs, G94 > A, G124 > A, and C245 > T (Li et al., 2012; Langaee et al., 2015). Genotyping analysis used a PSQ HS 96 system (Qiagen, Germantown, MD) and haplotypes computationally inferred from the unphased data (PHASE software, version 2.0.2; University of Chicago, IL). The protein concentration of subcellular fractions was measured by a Pierce bicinchoninic acid protein assay kit (Thermo Fisher Scientific, Waltham, MA).

GSTZ1 Activity Assay with DCA. GSTZ1 activity with DCA in human liver mitochondria and cytosol was measured by published methods (Li et al., 2011). Human liver mitochondrial samples were placed on ice and sonicated for 10 seconds (twice, with a 25 -second interval) to disrupt the mitochondrial membrane. Sonicated mitochondria samples were then dialyzed against $1.15 \% \mathrm{KCl}$ and $0.05 \mathrm{M}$ potassium phosphate buffer $(\mathrm{pH} 7.4)$ to remove sucrose, which has previously been shown to inhibit GSTZ1 activity. Assay tubes were incubated at $37^{\circ} \mathrm{C}$, with gentle shaking. The reaction mixture contained $0.4-0.9 \mathrm{mg}$ dialyzed protein, $200 \mu \mathrm{M} \mathrm{Na}\left[1-{ }^{14} \mathrm{C}\right]-\mathrm{DCA}, 5 \mathrm{mM} \mathrm{GSH}$, and $0.1 \mathrm{M}$ Hepes- $\mathrm{NaOH}$ ( $\mathrm{pH} 7.6$ ) in a total volume of $0.1 \mathrm{ml}$. The reaction was started by adding mitochondrial protein and vortex mixing, and then stopped after 30 minutes by the addition of ice-cold methanol to precipitate protein. These conditions were saturating for DCA and GSH and were linear for product formation. After centrifugation, the amount of $\left[{ }^{14} \mathrm{C}\right]$-glyoxylate formed in the filtered sample was determined by high-performance liquid chromatography with radiochemical detection. The enzyme activity is expressed as nanomoles glyoxylate per minute per milligram protein. For liver cytosol samples, samples were not sonicated; dialyzed protein of $0.05-0.1 \mathrm{mg}$ and $1 \mathrm{mM} \mathrm{GSH}$ were used in the assay with a 10-minute incubation time.

To study enzyme kinetics, activity assays were performed in which dialyzed samples of human liver cytosol or mitochondria $(0.1-0.5 \mathrm{mg}$ protein) were incubated with varying concentrations of GSH or $\left[1-{ }^{14} \mathrm{C}\right]$ NaDCA. To determine apparent kinetic constants for GSH, the concentration of NaDCA was $0.2 \mathrm{mM}$, and 8-10 GSH concentrations between 0.001 and $5 \mathrm{mM}$ were used. To determine apparent NaDCA kinetic constants, the GSH concentration was $5 \mathrm{mM}$ (mitochondria) or $1 \mathrm{mM}$ (cytosol) and eight NaDCA concentrations varied between 5 and $200 \mu \mathrm{M}$. Incubation times were 10 and 30 minutes for the cytosol and mitochondria samples, respectively (Li et al., 2012). GSTZ1 activity was measured as described previously. All samples were assayed in duplicate.

Measurement of GSH Consumption. To determine the stability of GSH in liver cytosol or mitochondria, human liver cytosol and sonicated mitochondria from adults (31-45 years of age), were dialyzed against $1.15 \% \mathrm{KCl}$ and $0.05 \mathrm{M}$ potassium phosphate buffer ( $\mathrm{pH} 7.4$ ) using $10 \mathrm{~K}$ molecular weight cutoff filters (Millipore, Billerica, MA), to remove GSH from these samples. The protein concentrations of the dialyzed samples were measured by Bio-Rad protein assay (Hercules, CA). Dialyzed cytosol or mitochondria samples, $300 \mu \mathrm{g}$ protein, were incubated with varying concentrations of GSH $(0.025-1 \mathrm{mM}), 0.1 \mathrm{M}$ Hepes- $\mathrm{NaOH}$ buffer ( $\mathrm{pH}$ 7.6), and water in a total volume of $100 \mu \mathrm{l}$ at $37^{\circ} \mathrm{C}$ with gentle shaking. After 0 and 10 minutes (cytosol) or 0 and 
30 minutes (mitochondria), $100 \mu \mathrm{l}$ of ice-cold methanol was added and tubes were centrifuged to precipitate protein. The GSH concentration in the supernatant was measured by derivatization and fluorescence spectrophotometry based on published methods (Hissin and Hilf, 1976). An aliquot of the supernatant $(0.012-0.12 \mathrm{ml})$ was incubated for 20 minutes with $1 \mathrm{ml}$ of $0.1 \mathrm{M}$ potassium phosphate buffer $(\mathrm{pH} 8)$ containing $0.005 \mathrm{M}$ EDTA, $0.1 \mathrm{ml}$ of $0.1 \% o$-phthalaldehyde prepared in methanol, and water to a total volume of $2.5 \mathrm{ml}$ at room temperature. Fluorescent intensity was measured by the LS 55 Luminescence Spectrometer (PerkinElmer, Waltham, MA) at excitation $350 \mathrm{~nm}$ and emission $420 \mathrm{~nm}$. A standard curve of known concentrations of GSH was used for quantitation. All samples were measured in duplicate.

$\boldsymbol{\gamma}$-Glutamyl Transpeptidase Activity. A spectrophotometric assay was used to determine $\gamma$-glutamyl transpeptidase (GGT) activity (Tate and Meister, 1977). Cuvettes contained $1 \mathrm{mM} \mathrm{L-} \gamma$-glutamyl-p-nitroanilide (Sigma Aldrich, St. Louis, MO), 20 mM glycylglycine (Sigma Aldrich), and $1 \mathrm{mg}$ of human liver mitochondria or cytosol from adults (31-45 years of age) in a total volume of $2 \mathrm{ml}$ of $0.1 \mathrm{M}$ Tris- $\mathrm{HCl}(\mathrm{pH} 8)$ at $37^{\circ} \mathrm{C}$. The absorbance at $410 \mathrm{~nm}$ was recorded each minute for 1 hour, and the linear change in absorbance between 1 and 30 minutes was used to calculate the concentration of $p$-nitroaniline released using the published molar extinction coefficient of $8800 \mathrm{~cm}^{-1}$.

Western Blot. Known amounts of mitochondrial protein (40-200 $\mu \mathrm{g})$ were used to develop blots, using a custom-prepared rabbit polyclonal antibody to human GSTZ1C (Li et al., 2012) together with a rabbit monoclonal antibody to a synthetic peptide corresponding to residues near the C-terminus of human ALDH1A1 (Abcam, Cambridge, MA), used as a marker of cytosolic contamination of the mitochondria. Both primary antibodies were diluted 1:2000. The amount of mitochondrial protein (40-200 $\mu \mathrm{g}$ ) loaded in the gel was guided by measured mitochondrial GSTZ1 activity with DCA. Each gel included $5 \mu \mathrm{g}$ of a single designated human liver cytosol as a reference control. After the blot was visualized and digitized by the Bio-Rad ChemiDoc MP Imaging System (Bio-Rad Laboratories, Hercules, CA), the intensity of bands was analyzed by Image Laboratory software (Bio-Rad Laboratories). Standard curves for GSTZ1 (monomeric molecular weight $25 \mathrm{kDa}$ ) were constructed using hGSTZ1C (Guo et al., 2006). To quantify test samples, the signal of each individual test sample was normalized against the reference control. The GSTZ1 content of individual samples was calculated by linear regression from the standard curves, expressed as nanograms of GSTZ1 per microgram of mitochondrial protein. All samples were measured in duplicate. The limit of quantitation was $0.5 \mathrm{ng}$ of hGSTZ1C. Quantitation of ALDH1A1 (molecular weight $55 \mathrm{kDa}$ ) was an estimate relative to the expression in the reference cytosol fraction, assuming a linear response to the antibody and taking into account the amount of protein in the lane.

Data Analysis. To investigate possible age-related thresholds for mitochondrial GSTZ1 activity and expression, a regression-tree analysis was done, with the expression or activity as outcome and age, variants, sex, and race as possible predictors. A least deviation optimization criterion was used, with 15 specified as the minimum number in a node that would allow further splitting and 5 seconds as the minimum number for a final node. The CART software program was used (Salford Systems, San Diego, CA), and a value of $P=0.05$ was considered statistically significant.

Comparisons of GSTZ1 expression and activity in mitochondria and cytosol were analyzed by GraphPad Prism version 6.0 (GraphPad Software Inc., San Diego, CA). For the enzyme kinetic experiments, the kinetic parameters [ $V_{\max }$, apparent $K_{\mathrm{m}}\left({ }^{\mathrm{App}} K_{\mathrm{m}}\right)$, and apparent $K^{\prime}\left({ }^{\mathrm{App}} K^{\prime}\right)$ ] were obtained from GraphPad Prism version 6.0 by fitting the data to the Michaelis-Menten and Hill equations. The best fit was determined by comparing results for the fit of each equation using Aikake's information criteria. The Michaelis-Menten equation is the following:

$$
v=\frac{V_{\max } \times[S]}{K_{m}+[S]}
$$

where $V_{\max }$ is the maximum enzyme velocity; $[S]$ is the substrate concentration; and $K_{\mathrm{m}}$ is the Michaelis-Menten constant, representing the substrate concentration needed to achieve a half-maximum velocity. The Hill equation is the following:

$$
v=\frac{V_{\max } \times[S]^{h}}{K_{\text {prime }}+[S]^{h}}
$$

where $h$ is the Hill slope; and $K_{\text {prime }}$ is the substrate concentration, in which the rate is one-half that of the $V_{\max }$ value.

Time Course of DCA-Induced Inactivation of GSTZ1. The DCAinduced GSTZ1 inactivation was assayed as previously described (Zhong et al., 2014). Human liver cytosol or sonicated mitochondria was dialyzed against $0.1 \mathrm{M}$ potassium phosphate buffer ( $\mathrm{pH}$ 7.4). Dialyzed mitochondria $(2 \mathrm{mg} / \mathrm{ml})$ or cytosol $(0.6 \mathrm{mg} / \mathrm{ml})$ was incubated with $0.5 \mathrm{mM} \mathrm{DCA}$, $5 \mathrm{mM} \mathrm{GSH}$, and $0.1 \mathrm{M}$ potassium phosphate $(\mathrm{pH} 7.4)$ in a volume of $500 \mu \mathrm{l}$ at $37^{\circ} \mathrm{C}$ for $0-90$ minutes in the absence of $\mathrm{KCl}$ or for $0-12$ hours in the presence of $38 \mathrm{mM} \mathrm{KCl}$; control groups were those with 0-hour incubation time. Unbound substrate and product were removed by ultrafiltration after incubation, using Amicon molecular weight cutoff filters $(10 \mathrm{kDa})$ following three concentration-dilution cycles. GSTZ1 activity of recovered protein was measured by the activity assay described previously. To determine the inactivation half-life $\left(t_{1 / 2}\right)$, the natural $\log$ of assay activity $(A)$ divided by control activity $\left(A_{0}\right.$, activity at time 0$)$ was plotted against time. Data were fitted to the equation $\ln \left(A / A_{0}\right)$ $=-k_{\mathrm{obs}} t$ with lines forced to go through $(0,0)$. The $t_{1 / 2}$ value was determined from the equation $t_{1 / 2}=\ln 2 / k_{\mathrm{obs}}$ (Zhong et al., 2014).

Immunoprecipitation of GSTZ1. Following previously described procedures ( $\mathrm{Li}$ et al., 2011), liver cytosol and mitochondria were obtained from $10 \mathrm{~g}$ of a human liver sample with the GSTZ1C/1C haplotype. The mitochondrial matrix was further separated from the mitochondrial fraction. Pierce phosphatase inhibitor mini tablets (Thermo Fisher Scientific) were added in all of the buffers used in subcellular fractionation and immunoprecipitation.

Procedures for immunoprecipitation were adapted from the manufacturer's instructions. In each batch, $10 \mu \mathrm{g}$ rabbit polyclonal anti-hGSTZ1C was incubated with $200 \mu$ l Protein A Magnetic Beads (Bio-Rad Laboratories) and $0.1 \%$ Tween 20 in phosphate-buffered saline with a total volume of $400 \mu \mathrm{l}$ at $4^{\circ} \mathrm{C}$ for 1 hour with rotation. Washed antibodycoupled magnetic beads were incubated with $500 \mu \mathrm{l}$ of $5 \mathrm{mM}$ bis [sulfosuccinimidyl]suberate solution freshly prepared in conjugation buffer $(20 \mathrm{mM}$ sodium phosphate and $0.15 \mathrm{M} \mathrm{NaCl}, \mathrm{pH} 7.8)$ and rotated at room temperature for 0.5 hours. To stop the reaction, $25 \mu \mathrm{l}$ of quenching buffer (1 M Tris- $\mathrm{HCl}, \mathrm{pH}$ 7.5) was added into the incubation mixture, and the mixture was rotated for 15 minutes. After washing, beads were incubated with $100 \mu \mathrm{l}$ of human liver cytosol or $400 \mu \mathrm{l}$ of liver mitochondria matrix at $4{ }^{\circ} \mathrm{C}$ overnight with rotation. Unbound protein was removed and $90 \mu \mathrm{l}$ of $20 \mathrm{mM}$ glycine elution buffer ( $\mathrm{pH} 2.0$ ) was added to beads to elute GSTZ1. The eluate was neutralized with $10 \mu \mathrm{l}$ of $1 \mathrm{M}$ potassium phosphate buffer, $\mathrm{pH}$ 7.4. The procedure was repeated, and several batches of eluate were combined and concentrated using molecular weight cutoff filters $(10 \mathrm{kDa})$. After concentration, samples were separated by SDS-PAGE and the gel was stained with Coomassie blue. Protein bands of cytosolic or mitochondrial GSTZ1 were cut out and stored at $-80^{\circ} \mathrm{C}$ for proteomic mass spectrometry analysis.

Analysis of Protein Phosphorylation by Mass Spectrometry. Gel bands obtained from immunoprecipitation were washed with water once and then destained with a $50 \%$ acetonitrile (ACN) in $50 \mathrm{mM}$ ammonium bicarbonate $(\mathrm{ABC})$ buffer. Proteins in the gel were reduced with $45 \mathrm{mM}$ 
dithiothreitol prepared in $\mathrm{ABC}$ buffer at $55^{\circ} \mathrm{C}$ for 45 minutes, following by 45-minute alkylation with $200 \mathrm{mM}$ iodoacetamide in $\mathrm{ABC}$ buffer at room temperature in the dark. Proteins were then digested with $10 \mathrm{ng} / \mu \mathrm{l}$ trypsin dissolved in $\mathrm{ABC}$ buffer at $37^{\circ} \mathrm{C}$ overnight. Peptides were extracted with $70 \%$ ACN including $0.1 \%$ of trifluoroacetic acid and lyophilized. Phosphopeptides were enriched with $\mathrm{TiO}_{2}$ NuTip microcolumns (GlygenSci, Columbia, MD) following the method described previously (Gates et al., 2010).

The lyophilized peptides (enriched and flow through) were solubilized in $10 \mu \mathrm{l}$ of loading buffer ( $3 \% \mathrm{ACN}, 0.1 \%$ acetic acid, and $0.01 \%$ trifluoroacetic acid), loaded onto a C18 capillary trap cartridge (LC Packings, Sunnyvale, CA), and then separated on a $15-\mathrm{cm}$ nanoflow analytical C18 column (PepMap $75 \mu \mathrm{m}$ i.d., $3 \mu \mathrm{m}, 100 \AA$ ) at a flow rate of $300 \mathrm{nl} / \mathrm{min}$ on a nanoLC ultra 1D plus system (ABsciex, Framingham, MA). Solvent A composition was 3\% ACN v/v and $0.1 \%$ acetic acid v/v, and the solvent $\mathrm{B}$ composition was $97 \% \mathrm{ACN}$ v/v and $0.1 \%$ acetic acid $\mathrm{v} / \mathrm{v}$. Peptide separation was performed with a linear gradient from $3 \%$ to $40 \%$ of solvent B for 20 minutes, followed by an increase to $90 \%$ of solvent B in 5 minutes and held for 5 minutes. The flow was directly sprayed to an LTQ Orbitrap-XL mass spectrometer (ThermoFisher, Bremen, Germany). Tandem mass spectrometry (MS/MS) spectra were acquired in a data-dependent mode. An Orbitrap full mass spectrometry scan (resolution: $3 \times 104$, mass range 400-1800 Da) was followed by $10 \mathrm{MS} / \mathrm{MS}$ scans in the ion trap, which were performed via collisioninduced dissociation of the top 10 most abundant ions. The isolation window for ion selection was $3 \mathrm{Da}$. Normalized collision energy was set at 28\%. Dynamic exclusion time was 20 seconds (Li et al., 2011). Additionally, if phosphate neutral losses of 98, 49, 32.66, and 24.5 massto-charge ratios below the precursor ion mass were detected, there was additional activation. The multistage activation event was repeated for the top five ions in a data-dependent manner, provided the precursor exceeded a threshold of 500 ion counts (Ulintz et al., 2008). An inclusion list of the peptides for the GSTZ1 N-terminal was included in the method.

Protein Search Algorithm. Tandem mass spectra were extracted by ABI Analyst (AB SCIEX, Toronto, Canada). Charge state deconvolution and deisotoping were not performed. All MS/MS samples were analyzed using Mascot (version 2.4.1; Matrix Science, London, United Kingdom). Mascot was set up to search the National Center for Biotechnology Information nr_20130403 database (selected for Homo sapiens; unknown version, 247,596 entries) assuming the digestion enzyme trypsin. Mascot was searched with a fragment ion mass tolerance of $0.50 \mathrm{Da}$ and a parent ion tolerance of $10.0 \mathrm{ppm}$. Carbamidomethyl of cysteine was specified in Mascot as a fixed modification. Glutamine $(\mathrm{Gln})>$ pyroglutamate of the N-terminus; deamidation of asparagine and Gln; and oxidation of methionine and phosphorylation of serine, threonine, and tyrosine were specified in Mascot as variable modifications. Scaffold version 4.3.4 (Proteome Software Inc., Portland, OR) was used to validate MS/MSbased peptide and protein identifications. Peptide identifications were accepted if they could be established at greater than $50.0 \%$ probability by the peptide prophet algorithm (Keller et al., 2002) with Scaffold deltamass correction. Protein identifications were accepted if they could be established at greater than $20.0 \%$ probability and contained at least one identified peptide. Protein probabilities were assigned by the protein prophet algorithm (Nesvizhskii et al., 2003). Proteins that contained similar peptides and could not be differentiated based on MS/MS analysis alone were grouped to satisfy the principles of parsimony. Proteins sharing significant peptide evidence were grouped into clusters.

\section{Results}

Age-Related Changes of GSTZ1 Expression and Activity in Human Liver Mitochondria. To determine the GSTZ1 expression level in human liver mitochondria, two GSTZ1 standard curves were constructed with ranges of $1.25-20$ and $0.5-1.75 \mathrm{ng}$, respectively (Supplemental Fig. 1). Among all mitochondrial samples, 101 out of 103 samples were calculated from standard curve 1 , with $5 \mu \mathrm{g}$ of the designated human liver cytosol sample as the reference control. The GSTZ1 contents of two mitochondrial samples were below the lower limit of standard curve 1 . Therefore, the blot was redone with longer exposure time, using $1 \mu \mathrm{g}$ of the designated cytosol sample as the reference control. Standard curve 2 was used to quantify these two samples. To test if mitochondrial samples were contaminated by cytosolic proteins, ALDH1A1 was used as a cytosolic marker on each blot to check mitochondria purity. The intensities of ALDH1A1 bands on the blot were much lower in human liver mitochondria compared with cytosol. Quantitation of the ALDH1A1 bands relative to the cytosol reference showed that the mitochondrial expression was $1.59 \% \pm 0.22 \%$ that of cytosol (mean \pm S.E.M., $n=93$ ), indicating mitochondria had very little contamination from cytosol. A representative blot of three samples of mitochondria is shown in Supplemental Fig. 2.

GSTZ1 expression in mitochondria was low in the first year after birth and increased with advancing age (Fig. 1, A and B). GSTZ1 activity showed a similar trend (Fig. 1, C and D). The log scale shown in Fig. 1, B and D emphasizes data for the early time points. Mitochondrial GSTZ1 protein expression (Fig. 2A) and enzyme activity with DCA (Fig. 2B) were divided into three groups, as indicated by the regression tree analysis, with age thresholds at 1 and 21 years old. Median mitochondrial GSTZ1 expression increased 2 -fold between the $>0$ to 1 year group and the $>1-$ 21 year group and increased another 2.5 - fold in the $>21-84$ year group (Fig. 2A). Among individuals of all ethnicities over 21 years old, there was no significant difference in hepatic mitochondrial GSTZ1 expression level between GSTZ1A carriers $(0.058 \pm 0.034 \mathrm{ng}$ GSTZ1 $/ \mu \mathrm{g}$ mitochondrial protein; mean \pm S.D., $n=8)$ and noncarriers (0.060 $\pm 0.027 \mathrm{ng} \mathrm{GSTZ1/}$ $\mu \mathrm{g}$ mitochondrial protein; mean \pm S.D., $n=38)$. However, mitochondrial GSTZ1 activity toward DCA in 1A carriers $(0.273 \pm 0.113 \mathrm{nmol}$ glyoxylate/min/mg; mean \pm S.D., $n=8)$ was significantly higher than that in 1 A noncarriers $(0.109 \pm 0.047 \mathrm{nmol}$ glyoxylate $/ \mathrm{min} / \mathrm{mg}$; mean \pm S.D., $n=38 ; P<0.0001)$, consistent with the haplotype difference observed in human liver cytosol samples ( $\mathrm{Li}$ et al., 2012). The significant differences for GSTZ1 expression and activity shown in Fig. 2 were determined by the nonparametric Kruskal-Wallis test with Dunn's multiple comparisons test. The activity data from the $131 \mathrm{~A}$ carriers were excluded in this analysis. A 2.7-fold increase was observed between the $>0$ to 1 year group and the $>$ 1-21 year group in the median GSTZ1 activity with DCA. The $>21-84$ year group increased another 2-fold (Fig. 2B). Between mitochondrial GSTZ1 expression and activity, the Pearson correlation $\left(r^{2}\right)$ was 0.81 for $1 \mathrm{~A}$ carriers and 0.90 for $1 \mathrm{~A}$ noncarriers (both $P<0.00001$; Fig. 3). Plots of the ratios of mitochondrial to cytosolic GSTZ1 expression (Fig. 4A) and enzyme activity (Fig. 4B) showed increasing trends as a function of age, with the slopes of the linear regression lines significantly larger than zero. This finding suggests that both mitochondrial GSTZ1 protein expression and GSTZ1 activity increased with age to a greater extent than their cytosolic counterparts.

Among five GSTZ1 haplotypes, GSTZ1A, 1B, and 1F possess a lysine amino acid $(\mathrm{K})$ at position 32 while other haplotypes have a glutamic acid amino acid (E). GSTZ1 expression data from individuals older than 21 years were analyzed by ethnicity, based on the presence of K. GSTZ1 expression in liver mitochondria was significantly lower in K carriers than in $\mathrm{K}$ noncarriers in Caucasians $(P<0.01$; Table 1$)$. This finding is consistent with previously published results showing that liver cytosolic GSTZ1 expression differed significantly between K carrier and noncarrier haplotypes in Caucasians (Langaee et al., 2015).

Properties of Mitochondrial Versus Cytosolic GSTZ1 Activity with DCA. Enzyme kinetics studies were conducted with adult human 

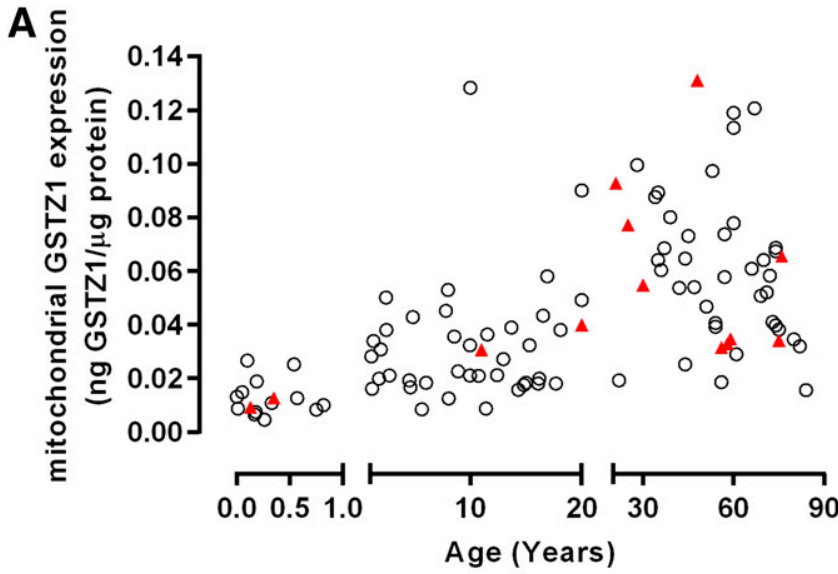

C

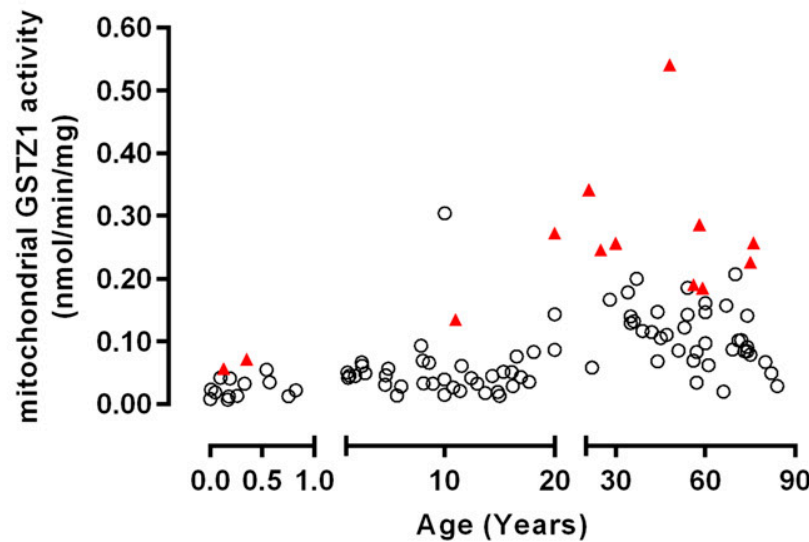

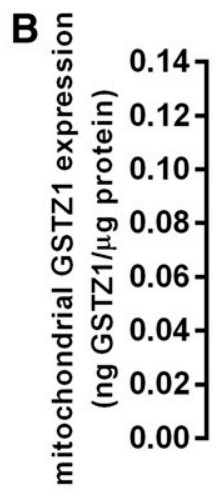

0.1

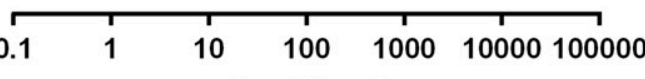

D

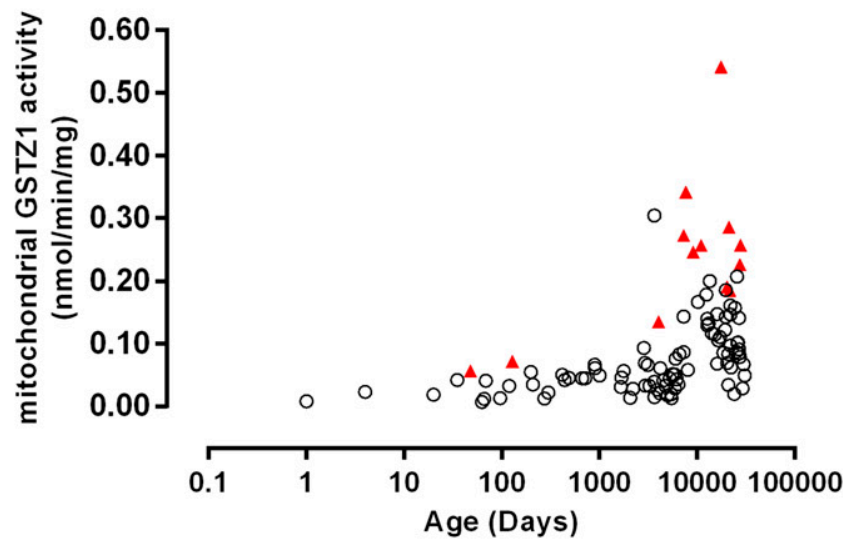

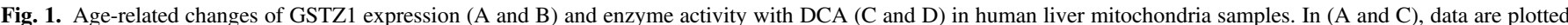

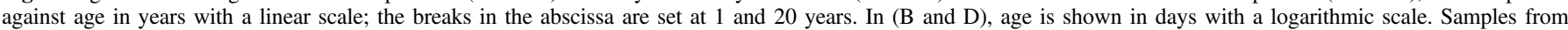

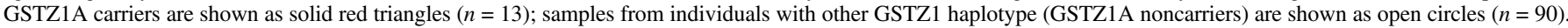

Data points represent the mean of duplicate measurements.

hepatic mitochondria and cytosol by separately varying GSH concentration or DCA concentration. Initial enzyme kinetic studies with GSH as the variable substrate showed the ${ }^{\text {App }} K_{\mathrm{M}}$ values for GSH in human hepatic mitochondria from adults was much higher than in cytosol. We investigated the possibility that liver mitochondria consumed GSH during these assays in the absence of DCA. Studies of the stability of GSH in mitochondria showed that at low micromolar concentrations, a substantial proportion of the added
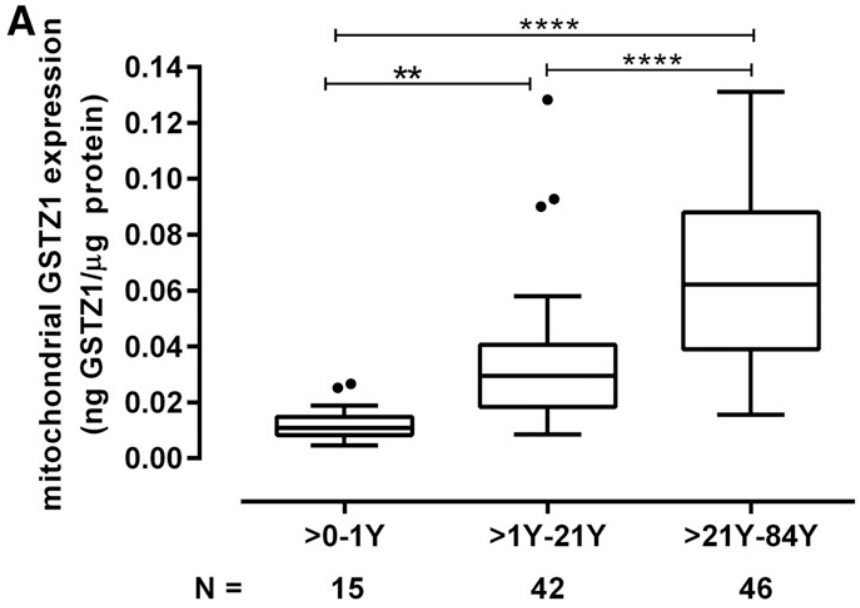

B

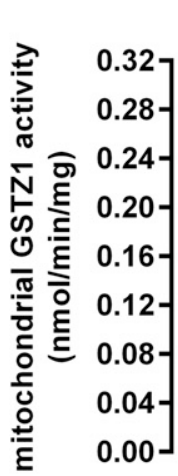

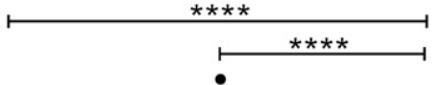
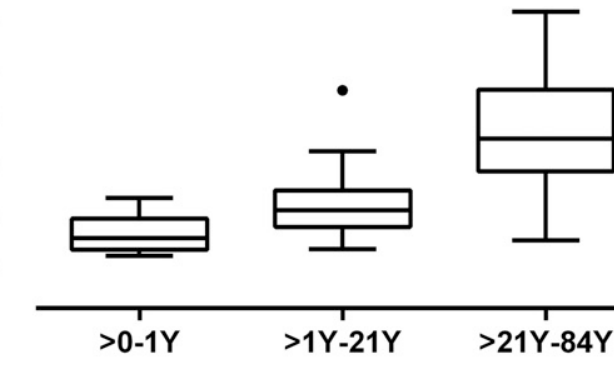

$\mathbf{N}=$

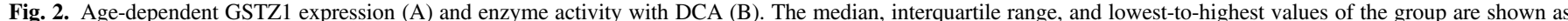

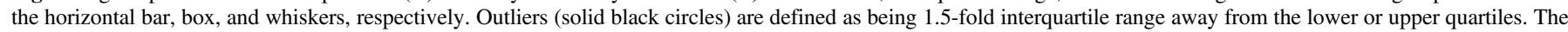

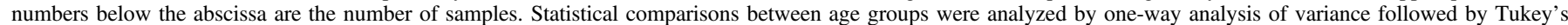
multiple comparisons; $* * P<0.01 ; * * * * P<0.0001$. 


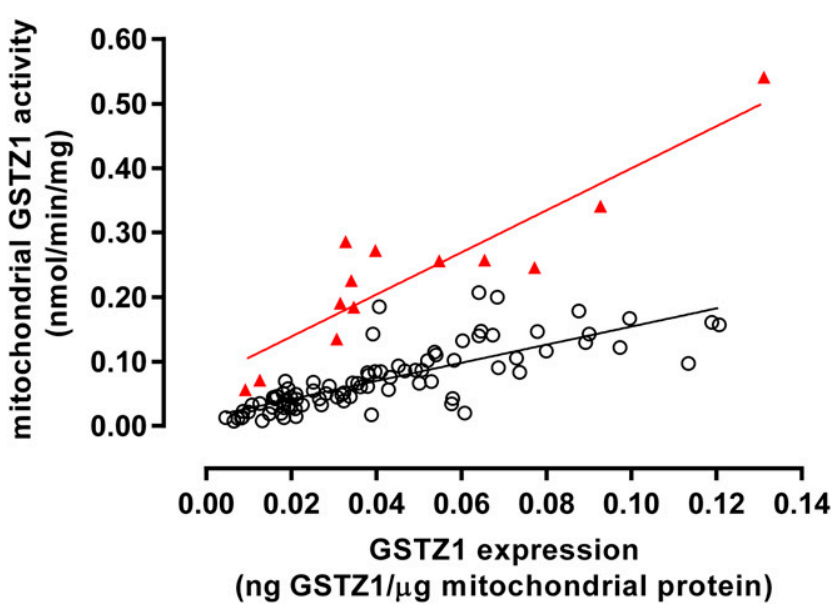

Fig. 3. Relationship between hepatic mitochondrial GSTZ1 expression and activity. GSTZ1A carriers are represented by solid red triangles $(n=13)$ with a red regression line $(\mathrm{y}=3.265 \mathrm{x}+0.073)$; GSTZ1A noncarriers are shown as open black circles $(n=$ $90)$ with a black regression line $(y=1.537 x+0.009)$. Values are the mean of duplicate determinations. The slopes of three regression lines are significantly larger than zero, with the value of $P<0.0001$.

GSH was depleted over the course of 30-minute incubation. These studies, as well as studies with cytosol, are described in detail in the next section. To calculate the ${ }^{\mathrm{App}} K_{\mathrm{M}}$ value for GSH in mitochondria, we corrected for the loss of GSH that occurred during assays. The Hill equation provided a better fit for the data in cytosol and mitochondria, as assessed by comparing the fit to that of the Michaelis-Menten equation using Aikake's information criteria (Akaike, 1974) in the GraphPad software. The curves are shown in Fig. 5A for cytosol and in Fig. 5B for mitochondria, and the kinetic constants are presented in Table 2. The Hill coefficient was greater than 1, indicating positive cooperativity. Similar ${ }^{\mathrm{App}} K^{\prime}$ values were found for mitochondria and cytosol. With DCA as the variable substrate, results from both the cytosolic and mitochondrial forms were better fitted to the MichaelisMenten equation (Fig. 5, C and D), with no significant difference in ${ }^{\mathrm{App}} K_{\mathrm{m}}$ values were obtained from samples with the GSTZ1C/1C haplotype in either subcellular fraction (Table 3). Cytosol from 1A/1C heterozygotes showed increased ${ }^{\mathrm{App}} V_{\max }$, as expected, and also had significantly higher ${ }^{\mathrm{App}} K_{\mathrm{m}}$ (Table 3). With either GSH or DCA as the variable substrate, the ${ }^{\mathrm{App}} V_{\max }$ values of mitochondrial GSTZ1 were significantly lower than cytosolic GSTZ1 (Tables 2 and 3).
TABLE 1

Human mitochondrial GSTZ1 expression related to the presence of lysine at position 32 of the protein in individuals over 21 years of age

Values shown are mean \pm S.D. (n). Significant difference between K32 carriers and noncarriers was analyzed by unpaired t test assuming equal variance; $* * \mathrm{P}=0.002$.

\begin{tabular}{|c|c|c|}
\hline \multirow{2}{*}{ Ethnic Group } & \multicolumn{2}{|c|}{ GSTZ1 Expression (ng GSTZ1/ $\mu \mathrm{g}$ Mitochondrial Protein) } \\
\hline & K Present & K Absent \\
\hline Caucasians & $0.038 \pm 0.013(n=11)$ & $0.059 \pm 0.013(n=8)^{* *}$ \\
\hline Other ethnicities ${ }^{a}$ & $0.099 \pm 0.024(n=4)$ & $0.067 \pm 0.035(n=3)$ \\
\hline
\end{tabular}

${ }^{a}$ Other ethnicities included African Americans, Hispanics, and others.

In the absence of chloride, both cytosolic GSTZ1 and mitochondrial GSTZ1 were inactivated rapidly by DCA (Fig. 6A; Table 4). At its physiologic concentration in the whole liver $(38 \mathrm{mM})$, the $t_{1 / 2}$ values of chloride-prolonged GSTZ1 were 6- to 10-fold in both human liver cytosol and mitochondria samples (Fig. 6B). Inactivation half-lives of cytosolic GSTZ1 were similar to those of mitochondrial GSTZ1 in the absence of chloride ( 0.54 and 0.63 hours, respectively), but $38 \mathrm{mM}$ chloride protected cytosolic GSTZ1 significantly more than mitochondrial GSTZ1. In the presence of $38 \mathrm{mM}$ chloride, the $t_{1 / 2}$ of cytosolic GSTZ1 was 5.15 hours and that of mitochondrial GSTZ1 was 3.83 hours $(P<0.01$; Table 4).

Based on calculated yields of mitochondrial and cytosolic protein of 35 and $50 \mathrm{mg} / \mathrm{g}$ liver, respectively (Björntorp et al., 1965), we estimated the contribution of hepatic mitochondria and cytosol to the initial metabolism of DCA to glyoxylate. In this estimate, we used activity data from subjects over 21 years of age, excluding those that were heterozygous for GSTZ1A. Cytosolic activity was $26.8 \pm 16.1 \mathrm{nmol}$ glyoxylate/min per gram liver (mean \pm S.D., $n=41$ ) and mitochondrial activity in the same samples was $3.9 \pm 1.9 \mathrm{nmol}$ glyoxylate/min per gram liver. Thus, assuming equal distribution of DCA throughout the liver cell, mitochondrial GSTZ1 would be responsible for $12.8 \%$ of the initial metabolism of DCA to glyoxylate. Given that DCA can enter mitochondria, its therapeutic site of action, mitochondrial GSTZ1 could play an important role in the initial metabolism of DCA.

Stability of GSH in Liver Cytosol and Mitochondria. To explore a possible reason for the differences in GSH enzyme kinetics between cytosolic and mitochondrial GSTZ1 in human liver, we tested if GSH was consumed under conditions identical to that of the GSTZ1 activity assay, but with no addition of DCA. Mitochondria but not cytosol depleted GSH in a concentration-dependent manner over a 30-minute
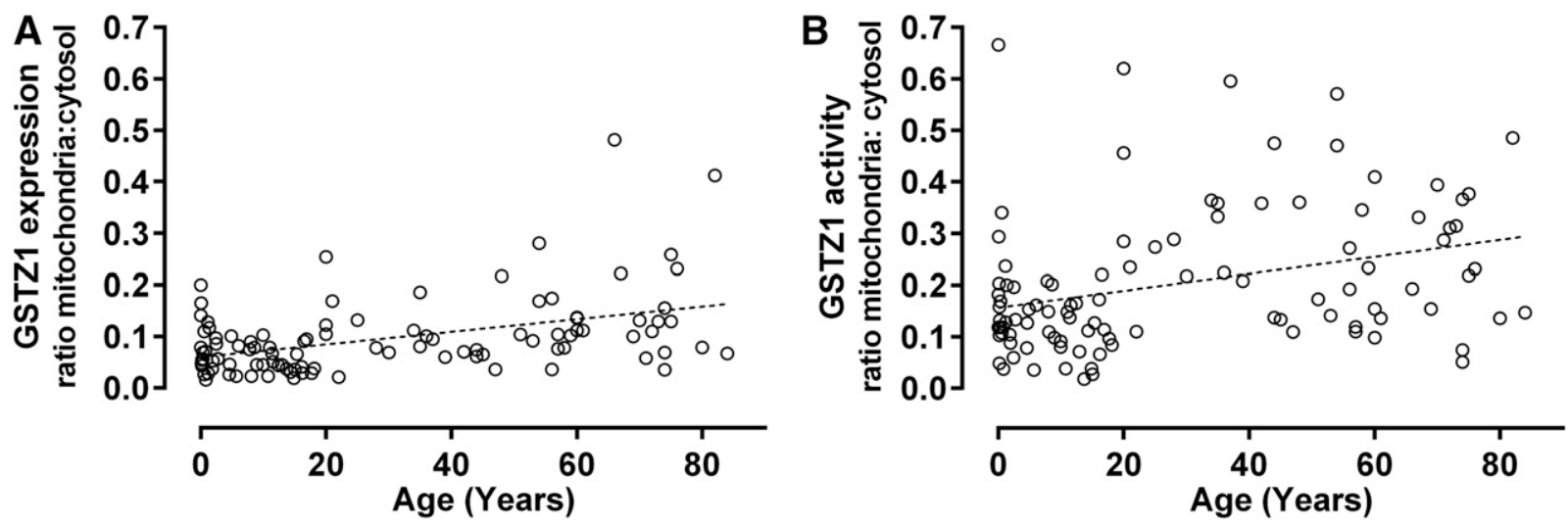

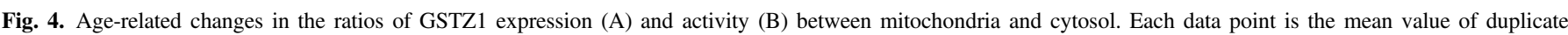

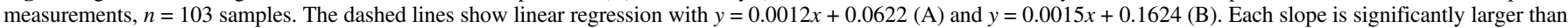
zero, $P<0.005$ 

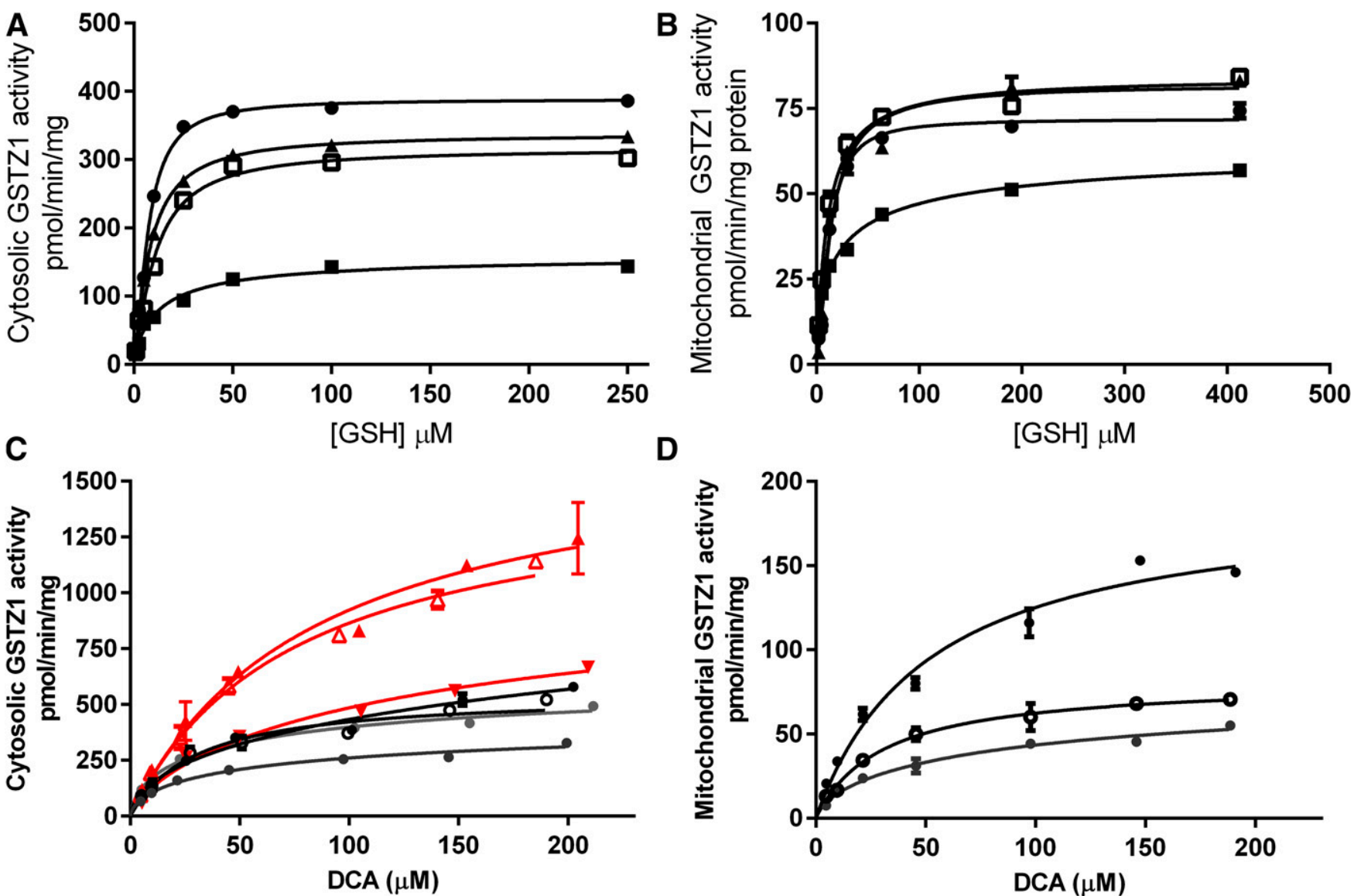

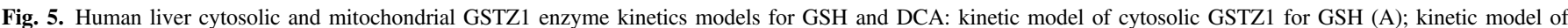

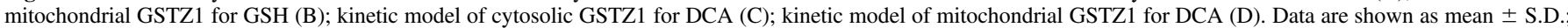

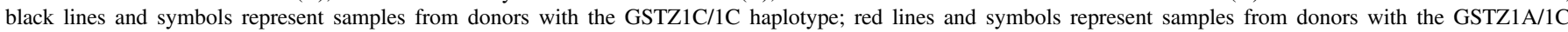
haplotype.

period (Fig. 7). These results were used to calculate the average concentration of GSH in studies of the apparent GSH kinetics of GSTZ1 in liver mitochondria, as noted previously.

$\gamma$-Glutamyl Transpeptidase Activity in Liver Mitochondria. GGT activity was found in adult human liver mitochondria, with linear increases in formation of $p$-nitroaniline from L- $\gamma$-glutamyl- $p$-nitroaniline occurring between 1 and 28 minutes. No GGT activity was detected in liver cytosol, whereas the mean mitochondrial enzyme activity was $0.67 \pm 0.13 \mathrm{nmol} / \mathrm{min}$ per milligram protein $(n=3)$.

Proteomic Analysis of GSTZ1. Post-translational phosphorylation of proteins can induce major changes in their function (Trost et al., 2010). To determine if phosphorylation differed in cytosolic GSTZ1and mitochondrial GSTZ1, immunoprecipitated cytosolic GSTZ1 and mitochondrial GSTZ1 were analyzed by proteomic mass spectrometry to identify phosphorylation site(s) of the protein. The sequence coverages

TABLE 2

Hill equation parameters of GSTZ1 enzyme kinetics for GSH

Data are expressed as mean $\pm S . D ., \mathrm{n}=4$ per group; $0.2 \mathrm{mM}\left[1-{ }^{14} \mathrm{C}\right] \mathrm{NaDCA}$ was used in incubations; $* * \mathrm{P}=0.0148$, significant difference between ${ }^{A p p} \mathrm{~V}$ values for cytosolic GSTZ1 and mitochondrial GSTZ1 for samples with 1C/IC haplotype (paired two-tailed $\mathrm{t}$ test).

\begin{tabular}{lcc}
\hline \multicolumn{1}{c}{ Parameter } & Cytosolic GSTZ1 & Mitochondrial GSTZ1 \\
\hline${ }^{\mathrm{App}} V(\mathrm{pmol} / \mathrm{mg} / \mathrm{min})$ & $301 \pm 98$ & $79.4 \pm 13.8^{* *}$ \\
${ }^{\mathrm{App}} K^{\prime}(\mu \mathrm{M})$ & $9.6 \pm 2.6$ & $14.5 \pm 5.0$ \\
$\mathrm{Hill}$ coefficient & $1.20 \pm 0.29$ & $1.17 \pm 0.42$
\end{tabular}

were $64 \%, 65 \%$, and $72 \%$, for cytosolic, mitochondrial, and human recombinant GSTZ1C, respectively (Fig. 8). The same covered sequence was shared by cytosolic and mitochondrial GSTZ1. Phosphorylated amino acids were not detected in either cytosolic or mitochondrial GSTZ1. Only one phosphorylated serine at position 188 was observed in human recombinant GSTZ1C (Fig. 7; Table 5). Other modifications, including Gln $>$ pyroglutamate of the N-terminus, deamidation of asparagine and Gln, and oxidation of methionine, were similar between two forms of GSTZ1, except that asparagine (N) at position 190 was deamidated in cytosolic GSTZ1 but not in mitochondrial GSTZ1 (Table 5).

TABLE 3

Parameters of GSTZ1 enzyme kinetics for DCA

Data are expressed as mean \pm S.D. The GSH concentration in the incubation was $1 \mathrm{mM}$ for cytosolic GSTZ1 and $5 \mathrm{mM}$ for mitochondrial GSTZ1. The data fit the Michaelis-Menten mode better than the Hill equation.

\begin{tabular}{lcccc}
\hline \multirow{2}{*}{ Haplotype } & \multicolumn{2}{c}{ Cytosolic GSTZ1 } & & Mitochondrial GSTZ1 \\
\cline { 2 - 3 } & $1 \mathrm{C} / 1 \mathrm{C}(n=4)$ & $1 \mathrm{~A} / 1 \mathrm{C}(n=3)$ & & $1 \mathrm{C} / 1 \mathrm{C}(n=3)$ \\
\hline${ }^{\mathrm{App}} V_{\max }(\mathrm{pmol} / \mathrm{mg} / \mathrm{min})$ & $486 \pm 122$ & $1250 \pm 372^{a}$ & & $111 \pm 69^{b}$ \\
${ }^{\mathrm{App}} K_{\mathrm{M}}(\mu \mathrm{M})$ & $26.2 \pm 6.8$ & $66.1 \pm 2.4^{c}$ & & $41.97 \pm 14.97$ \\
\hline
\end{tabular}

${ }^{a}$ Significant difference between haplotypes for values of cytosolic ${ }^{\mathrm{App}} V_{\max } ; P=0.002$.

${ }^{b}$ Significant difference between cytosolic and mitochondrial ${ }^{\mathrm{App}} V_{\max }$, both with GSTZ1C/1C haplotype, was analyzed by two-tailed $t$ test assuming equal variance; $P=0.0002$.

${ }^{c}$ Significant difference between haplotypes for values of cytosolic ${ }^{\mathrm{App}} K_{\mathrm{M}} ; P=0.002$. 

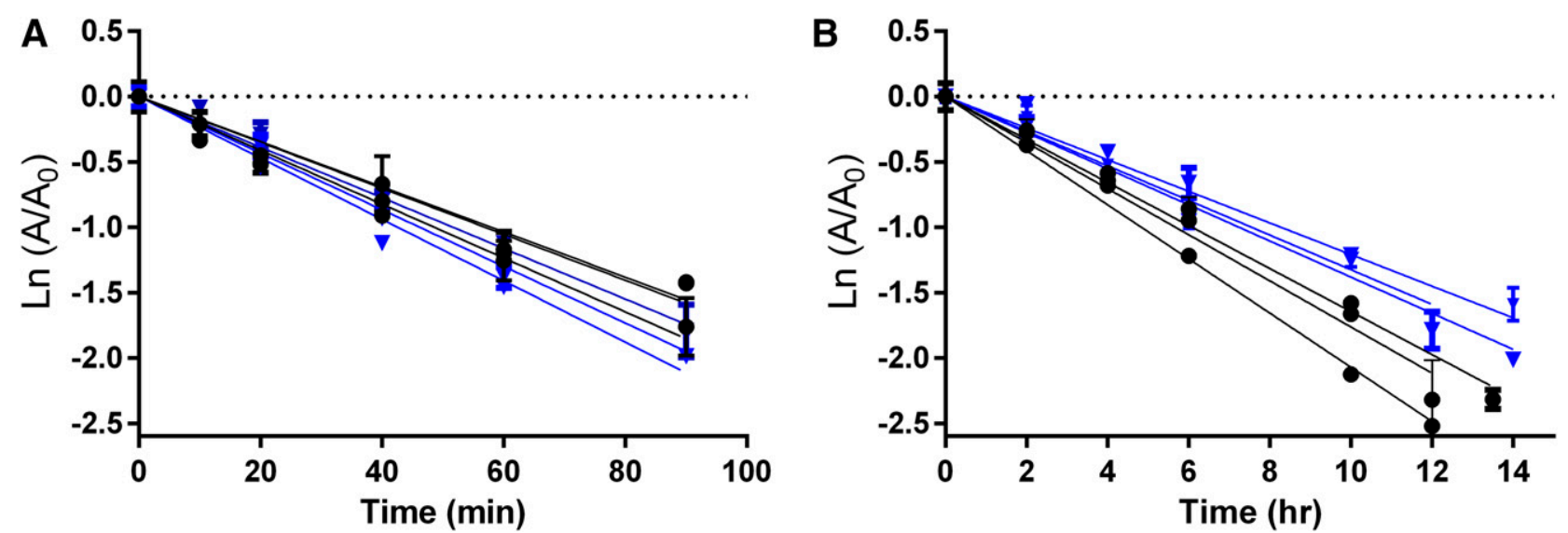

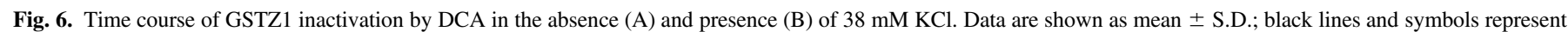
human liver mitochondria samples; blue lines and symbols represent cytosol samples. All liver samples are from donors with the GSTZ1C/1C haplotype.

\section{Discussion}

Molecules of one protein being expressed in more than one subcellular compartment is a common phenomenon in eukaryotic cells, and is referred to as dual localization or dual targeting (Kisslov et al., 2014). Differently localized proteins, but with identical or nearly identical protein sequence, are defined as echoforms or echoproteins. Echoforms exhibit the same or in some cases, surprisingly distinct activities and functions in each subcellular location (Raza, 2011; Yogev and Pines, 2011). Our previous studies ( $\mathrm{Li}$ et al., 2011) have identified both mitochondria and cytosol as subcellular expression sites of GSTZ1, based on immunoreactivity, enzyme reaction, and partial protein sequence $(<15 \%)$. However, the enzyme properties of liver mitochondrial GSTZ1 were incompletely understood. Considering the importance of mitochondrial GSTZ1 to DCA metabolism, in this study we extended our investigation on mitochondrial GSTZ1 using human samples. One of the aims was to investigate the developmental pattern of human liver mitochondrial GSTZ1, an important characteristic of liver cytosolic GSTZ1 in humans. Although 99\% mitochondrial proteins are encoded by nuclear genes, synthesized by the cytosolic ribosomes and translocated into mitochondria (Harbauer et al., 2014), the regulatory mechanisms of protein translocation from cytosol to mitochondria are incompletely understood. There are few studies on the relative developmental patterns of echoforms of proteins. The development of carboxylesterases 1 and 2, which exhibit microsomal and cytosolic expression, was examined in human liver samples and subtle differences in the developmental patterns were observed (Hines et al., 2016; Boberg et al., 2017).

Our results reveal that human liver mitochondrial GSTZ1 protein expression and activity, like cytosolic GSTZ1, were directly associated with subject age. However, some differences in the developmental

TABLE 4

The influence of chloride on GSTZ1 inactivation half-lives

Values shown are mean $\pm S . D ., \mathrm{n}=3$. Cytosol and mitochondria were obtained from three human liver samples with GSTZ1C/1C haplotype; $* \mathrm{P}=0.02$, comparing inactivation $\mathrm{t}_{1 / 2}$ between cytosolic and mitochondrial GSTZ1 (paired $\mathrm{t}$ test).

\begin{tabular}{lcc}
\hline \multirow{2}{*}{ GSTZ1 } & \multicolumn{2}{c}{ Average Half-Lives } \\
\cline { 2 - 3 } & $\frac{\text { Without } \mathrm{Cl}^{-}}{h}$ & $\frac{\text { With } \mathrm{Cl}^{-}(38 \mathrm{mM})}{h}$ \\
\cline { 2 - 3 } Cytosolic & $0.54 \pm 0.05$ & $5.15 \pm 0.11$ \\
Mitochondrial & $0.63 \pm 0.06$ & $3.83 \pm 0.44^{*}$ \\
\hline
\end{tabular}

pattern of GSTZ1 between the two subcellular compartments were found. For example, GSTZ1 expression in human liver mitochondria reached a plateau after the donor age of 21 years, whereas cytosolic GSTZ1 protein expression became relatively stable after 7 years of age (Li et al., 2012). The difference in age thresholds could result from different sample sizes and age distribution in the two sets of liver samples. Cytosol samples included in previously published results totaled 249, with 133 from donors $>0-7$ years old and 55 from donors $>7-74$ years old ( $\mathrm{Li}$ et al., 2012). In contrast, in the current study, the number of liver mitochondria samples from donors $>0-7$ years old was 28 , and the other 75 samples were from donors $>7-84$ years old. However, examination of the results for cytosolic expression of GSTZ1 in the livers used in this study showed the same developmental pattern as found previously ( $\mathrm{Li}$ et al., 2012), i.e., protein expression reached adult levels after 7 years of age (Supplemental Fig. 3). Of interest, the GSTZ1 expression ratio of mitochondria to cytosol, together with the GSTZ1 activity ratio, demonstrated an age-related increasing trend (Fig. 4). These data indicate that the relative contribution to DCA metabolism made by mitochondrial GSTZ1, compared with cytosolic GSTZ1,

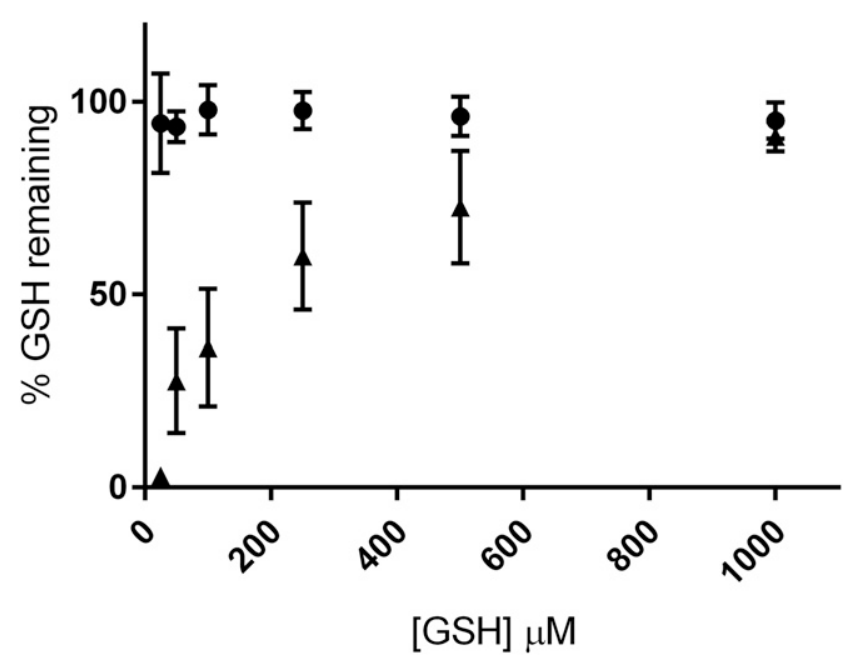

Fig. 7. Stability of various concentrations of GSH during a 30-minute incubation with cytosol (solid circles) and mitochondria (solid triangles). The concentrations of GSH shown were incubated with $0.3 \mathrm{mg}$ hepatic mitochondrial or cytosolic protein for 0 or 30 minutes, and then the remaining GSH was measured fluorimetrically following derivatization with $o$-phthalaldehyde. Points shown are mean \pm S.D. of three different liver samples. 


\section{A 1 MQAGKPILYS YFRSSCSWRV RIALALKGID YETVPINLIK DGGQQFSKDF QALNPMKQVP \\ 61 TLKIDGITIH QSLAIIEYLE ETRPTPRLLP QDPKKRASVR MISDLIAGGI QPLQNLSVLK \\ 121 QVGEEMQLTW AQNAITCGFN ALEQILQSTA GIYCVGDEVT MADLCLVPQV ANAERFKVDL \\ 181 TPYPTISSIN KRLLVLEAFQ VSHPCRQPDT PTELRA}

\section{B 1 MQAGKPILYS YFRSSCSWRV RIALALKGID YETVPINLIK DGGQQFSKDF QALNPMKQVP \\ 61 TLKIDGITIH QSLAIIEYLE ETRPTPRLLP QDPKKRASVR MISDLIAGGI QPLQNLSVLK \\ 121 QVGEEMQLTW AQNAITCGFN ALEQILQSTA GIYCVGDEVT MADLCLVPQV ANAERFKVDL \\ 181 TPYPTISSIN KRLLVLEAFQ VSHPCRQPDT PTELRA}

\section{1 MQAAGKPILYS YFRSSCSWRV RIALALKGID YETVPINLIK DGGQQFSKDF QALNPMKQVP \\ 61 TLKIDGITIH QSLAIIEYLE ETRPTPRLLP QDPKKRASVR MISDLIAGGI QPLQNLSVLK \\ 121 QVGEEMQLTW AQNAITCGFN ALEQILQSTA GIYCVGDEVT MADLCLVPQV ANAERFKVDL \\ 181 TPYPTISSIN KRLLVLEAFQ VSHPCRQPDT PTELRA}

Fig. 8. Mass spectrometry (MS) analysis of protein sequence and post-translational modifications of human liver cytosolic GSTZ1 (A), mitochondrial GSTZ1 (B), and hGSTZ1 (C). Peptide fragments highlighted in yellow are covered by MS; amino acids highlighted in green are modification sites.

increases as a function of age, even though cytosol is still the major subcellular location of DCA metabolism in cells. It is noteworthy that GSTZ1 mRNA levels do not correlate well with protein expression (Langaee et al., 2015). Further studies are needed to investigate the factors that influence the developmental pattern of GSTZ1.

There were similarities in the properties of cytosolic GSTZ1 and mitochondrial GSTZ1. Polymorphic variants exhibited the same properties for GSTZ1 activity with DCA in both locations, in that activity was significantly higher in liver samples from donors carrying the $1 \mathrm{~A}$ variant compared with all other variants (Blackburn et al., 2000; Li et al., 2012). The difference between the $1 \mathrm{~A}$ variant and other variants is that the $1 \mathrm{~A}$ variant has arginine at position 42 and all other variants express glycine at this position; however, the reason this affects activity is unclear. Another similarity in properties between cytosolic and mitochondrial GSTZ1 was that, as found previously for cytosolic GSTZ1 (Langaee et al., 2015), protein expression was significantly lower in mitochondria from Caucasian individuals who carried the gene variant coding for lysine at position 32 (variants $1 \mathrm{~A}, 1 \mathrm{~B}$, and $1 \mathrm{~F}$ ) than in those who expressed glutamic acid at this position (variants $1 \mathrm{C}$ and $1 \mathrm{D}$ ). This phenomenon is due to linkage disequilibrium between a promoter region SNP, G > A - 1002 (rs7160195) and coding region nonsynonymous SNP G > A 94 (rs7975), which occurs in Caucasians but not Africans (our two main ethnic groups). The ${ }^{\mathrm{App}} K_{\mathrm{m}}$ value for DCA was similar in cytosol and mitochondria from individuals with the EGT/ EGT (GSTZ1C/1C) variant. Initial studies indicated differences in the ${ }^{\mathrm{App}} K^{\prime}$ values for GSH between mitochondria and cytosol, but further investigation showed that these differences were because low concentrations of GSH were consumed by mitochondria during the course of the assay. The finding of GSH consumption and low GGT activity in adult human liver mitochondria was somewhat surprising since it has been reported that the mitochondrial pool of GSH is stable in rat liver (Meredith and Reed, 1982). There is, however, low gene expression of GGT in adult liver and the gene is expressed at higher levels in fetal liver (Ikeda and Taniguchi, 2005). GGT was found on the plasma membrane of the biliary canaliculi of the hepatocyte (Hanigan and Frierson, 1996). Plasma membrane components co-sediment with mitochondria (Suski et al., 2014); moreover, we did not use sucrose density gradients to isolate mitochondria because of the small amount of donor liver tissue available. Therefore, it is probable that contamination with plasma membrane components is the source of GGT in our mitochondrial

TABLE 5

Peptide sequences of GSTZ1C with post-translational modification sites

Bold, underlined amino acids were modified; unknown indicates sequence not covered.

\begin{tabular}{|c|c|c|c|c|}
\hline Sequence & Modification & Cytosolic GSTZ1C & Mitochondrial GSTZ1C & hGSTZ1C \\
\hline (M)QAGKPILYSYFR(S) & Gln $>$ Pyro-Glu & Unknown & Unknown & Y \\
\hline (K)DFQALNPMK(Q) & Gln $>$ Pyro-Glu ${ }^{a}$ & $\mathrm{~N}$ & $\mathrm{~N}$ & $\mathrm{Y}$ \\
\hline (K)DFQALNPMK(Q) & Oxidation & $\mathrm{Y}$ & $\mathrm{Y}$ & $\mathrm{Y}$ \\
\hline (K)QVPTLKIDG & Gln $>$ Pyro-Glu $^{a}$ & $\mathrm{~N}$ & $\mathrm{~N}$ & $\mathrm{Y}$ \\
\hline (R) $\overline{\mathbf{M}}$ ISDLIAGGIQPLQNLSVLK(Q) & Oxidation & Y & $\mathrm{Y}$ & $\mathrm{Y}$ \\
\hline 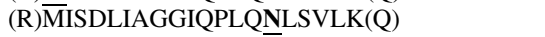 & Deamidated & $\mathrm{N}$ & $\mathrm{N}$ & Y \\
\hline (R)FKVDLTPYPTISSINKR & Phosphorylation & $\mathrm{N}$ & $\mathrm{N}$ & Y \\
\hline (R)FKVDLTPYPTISSINKR & Deamidated & Y & $\mathrm{N}$ & $\mathrm{Y}$ \\
\hline (R)QPDTPTELRA - & Gln $>$ Pyro-Glu ${ }^{a}$ & $\mathrm{Y}$ & $\mathrm{Y}$ & $\mathrm{Y}$ \\
\hline
\end{tabular}

$\mathrm{N}$, modification not found; Pyro-Glu, pyroglutamate; $\mathrm{Y}$, modification found.

${ }^{a}$ Pyroglutamate is formed from cyclization of N-terminal glutamine. 
preparations. At concentrations of GSH above $1 \mathrm{mM}$, within the reported physiologic range of 4-10 $\mathrm{mM}(\mathrm{Lu}, 2013)$, the loss of GSH over a 30-minute incubation with mitochondria was very low. We did not examine the influence of age on GSH consumption. After correcting for loss of low micromolar concentrations of GSH during the GSTZ1 assay, the GSH requirements for DCA metabolism were similar for mitochondria and cytosol. It is noteworthy that the ${ }^{\mathrm{App}} K^{\prime}$ for GSH (less than $20 \mu \mathrm{M}$, Table 2) is considerably lower than the physiologic concentration of GSH in either compartment, reported to be similar in liver mitochondria and cytosol (Ribas et al., 2014).

There were differences in the properties of the two GSTZ1 echoforms. As discussed previously, the developmental profile differed. Chloride attenuation of DCA-induced GSTZ1 inactivation in human liver cytosol was recently discovered by our group (Zhong et al., 2014), although the mechanism is still not elucidated. This phenomenon was observed in human liver mitochondria. In the absence of chloride, the inactivation half-lives of cytosolic GSTZ1 were similar to those of the mitochondrial counterpart. However, the two echoforms exhibited different inactivation half-lives of GSTZ1 in the presence of chloride, with more rapid inactivation of the mitochondrial form. Finding GGT activity in liver mitochondria but not cytosol raised the possibility that GSH consumption in mitochondria contributed to the faster inactivation; however, since the studies of inactivation were carried out in the presence of $5 \mathrm{mM} \mathrm{GSH}$, considerably higher than the mitochondrial ${ }^{\mathrm{App}} K^{\prime}$ for GSH, it is unlikely that the consumption of GSH by mitochondria was the cause of this difference in the inactivation rate of GSTZ1 in the presence of chloride.

Our findings provide a plausible explanation for the observed agerelated differences in DCA pharmacokinetics and toxicity. The contribution of mitochondrial GSTZ1 to total GSTZ1 increases with age (Fig. 4); therefore, the combination of very low $\left[\mathrm{Cl}^{-}\right]$in mitochondria compared with cytosol (Jahn et al., 2015) and more rapid inactivation of mitochondrial GSTZ1 (Fig. 6) suggests that the contribution of mitochondria to DCA metabolism will be quickly lost in repeated DCA treatment.

Based on the differences between mitochondrial and cytosolic GSTZ1, we first speculated that there may be amino acid differences in the primary protein sequences or different post-translational modifications (e.g., phosphorylation). Multiple studies have reported that mitochondrial protein import can be regulated by post-translational phosphorylation, for example, GSTA4, CYP2B1, and CYP2E1 (Anandatheerthavarada et al., 1999; Robin et al., 2002, 2003). Studies by Board et al. (2003) identified the motif consisting of serine 14, serine 15 , and cysteine 16 as involved in GSH binding, with serine 14 as the amino acid critical for GSH binding. Both serine 14 and 15 are potential phosphorylation sites, as well as 10 other serine residues in the GSTZ1 sequence. However, our proteomic mass spectrometry data revealed that no difference was detected between these two echoforms of GSTZ1, either in amino acids covered in the protein sequence $(>60 \%)$ or in posttranslational phosphorylation. Even though cytosolic GSTZ1 possessed a deamidated Asp190, while mitochondrial GSTZ1 did not, deamidation can happen naturally during mass spectrometry sample preparation. In addition, Asp190 is relatively distant from the active site, based on the protein's crystal structure (Polekhina et al., 2001; Boone et al., 2014). As a result, it is unlikely that the deamidation status of Asp190 can lead to the differences observed between the two forms of GSTZ1.

In summary, we demonstrated an age-related increase in the expression of human hepatic mitochondrial GSTZ1, although with a different pattern to what is reported for cytosolic GSTZ1. Mitochondrial GSTZ1 activity was well correlated with GSTZ1 expression. Even though cytosolic GSTZ1 and mitochondrial GSTZ1 differed in the age-related development pattern and the half-lives of GSTZ1 inactivation in the presence of chloride, covered protein sequence and post-translational modifications, particularly phosphorylation, are identical between these two forms of GSTZ1. Low micromolar concentrations of GSH were consumed during incubation with dialyzed liver mitochondria but not with cytosol. However, this difference does not explain the developmental pattern and stability differences found between the echoforms, which are foci of future investigations.

\section{Acknowledgments}

We thank the University of Florida Interdisciplinary Center for Biotechnology Research for performing the proteomics mass spectrometry.

\section{Authorship Contributions}

Participated in research design: Zhong, James, Stacpoole, Langaee.

Conducted experiments: Zhong, Smeltz, Jahn, Langaee, James.

Performed data analysis: Zhong, James, Smeltz, Jahn, Langaee, Simpson.

Wrote or contributed to the writing of the manuscript: Zhong, James, Stacpoole, Simpson, Langaee, Jahn.

\section{References}

Akaike H (1974) A new look at the statistical model identification. IEEE Trans Autom Control AC19:716-723.

Anandatheerthavarada HK, Biswas G, Mullick J, Sepuri NB, Otvos L, Pain D, and Avadhani NG (1999) Dual targeting of cytochrome P4502B1 to endoplasmic reticulum and mitochondria involves a novel signal activation by cyclic AMP-dependent phosphorylation at ser128. EMBO J 18:5494-5504.

Björntorp P, Björkerud S, and Scherstén T (1965) Subcellular fractionation of human liver. Biochim Biophys Acta 111:375-383.

Blackburn AC, Tzeng HF, Anders MW, and Board PG (2000) Discovery of a functional polymorphism in human glutathione transferase zeta by expressed sequence tag database analysis. Pharmacogenetics 10:49-57.

Board PG and Anders MW (2011) Glutathione transferase zeta: discovery, polymorphic variants, catalysis, inactivation, and properties of Gstz1 $1^{-1-}$ mice. Drug Metab Rev 43:215-225.

Board PG, Taylor MC, Coggan M, Parker MW, Lantum HB, and Anders MW (2003) Clarification of the role of key active site residues of glutathione transferase zeta/maleylacetoacetate isomerase by a new spectrophotometric technique. Biochem J 374:731-737.

Boberg M, Vrana M, Mehrotra A, Pearce RE, Gaedigk A, Bhatt DK, Leeder JS, and Prasad B (2017) Age-dependent absolute abundance of hepatic carboxylesterases (CES1 and CES2) by LC-MS/MS proteomics: application to PBPK modeling of oseltamivir in vivo pharmacokinetics in infants. Drug Metab Dispos 45:216-223.

Boone CD, Zhong G, Smeltz M, James MO, and McKenna R (2014) Preliminary X-ray crystallographic analysis of glutathione transferase zeta 1 (GSTZ1a-1a). Acta Crystallogr F Struct Biol Commun 70:187-189.

Gates MB, Tomer KB, and Deterding LJ (2010) Comparison of metal and metal oxide media for phosphopeptide enrichment prior to mass spectrometric analyses. J Am Soc Mass Spectrom 21 1649-1659.

Guo X, Dixit V, Liu H, Shroads AL, Henderson GN, James MO, and Stacpoole PW (2006) Inhibition and recovery of rat hepatic glutathione $S$-transferase zeta and alteration of tyrosine metabolism following dichloroacetate exposure and withdrawal. Drug Metab Dispos 34:36-42

Hanigan MH and Frierson HF, Jr (1996) Immunohistochemical detection of gamma-glutamyl transpeptidase in normal human tissue. J Histochem Cytochem 44:1101-1108.

Harbauer AB, Zahedi RP, Sickmann A, Pfanner N, and Meisinger C (2014) The protein import machinery of mitochondria-a regulatory hub in metabolism, stress, and disease. Cell Metab 19: 357-372.

Hines RN, Simpson PM, and McCarver DG (2016) Age-dependent human hepatic carboxylesterase 1 (CES1) and carboxylesterase 2 (CES2) postnatal ontogeny. Drug Metab Dispos 44:959-966. Hissin PJ and Hilf R (1976) A fluorometric method for determination of oxidized and reduced glutathione in tissues. Anal Biochem 74:214-226.

Ikeda Y and Taniguchi N (2005) Gene expression of $\gamma$-glutamyltranspeptidase. Methods Enzymol 401:408-425.

Jahn SC, Rowland-Faux L, Stacpoole PW, and James MO (2015) Chloride concentrations in human hepatic cytosol and mitochondria are a function of age. Biochem Biophys Res Commun 459:463-468.

Jahn SC, Smeltz MG, Hu Z, Rowland-Faux L, Zhong G, Lorenzo RJ, Cisneros KV, Stacpoole PW, and James MO (2018) Regulation of dichloroacetate biotransformation in rat liver and extrahepatic tissues by GSTZ1 expression and chloride concentration. Biochem Pharmacol 152: 236-243.

James MO, Cornett R, Yan Z, Henderson GN, and Stacpoole PW (1997) Glutathione-dependent conversion to glyoxylate, a major pathway of dichloroacetate biotransformation in hepatic cytosol from humans and rats, is reduced in dichloroacetate-treated rats. Drug Metab Dispos 25: $1223-1227$.

James MO, Jahn SC, Zhong G, Smeltz MG, Hu Z, and Stacpoole PW (2017) Therapeutic applications of dichloroacetate and the role of glutathione transferase zeta-1. Pharmacol Ther 170: $166-180$.

James MO and Stacpoole PW (2016) Pharmacogenetic considerations with dichloroacetate dosing. Pharmacogenomics 17:743-753.

James MO, Yan Z, Cornett R, Jayanti VM, Henderson GN, Davydova N, Katovich MJ, Pollock B, and Stacpoole PW (1998) Pharmacokinetics and metabolism of $\left[{ }^{14} \mathrm{C}\right]$ dichloroacetate in male Sprague-Dawley rats. Identification of glycine conjugates, including hippurate, as urinary metabolites of dichloroacetate. Drug Metab Dispos 26:1134-1143.

Kankotia S and Stacpoole PW (2014) Dichloroacetate and cancer: new home for an orphan drug? Biochim Biophys Acta 1846:617-629. 
Kaufmann P, Engelstad K, Wei Y, Jhung S, Sano MC, Shungu DC, Millar WS, Hong X, Gooch CL, Mao X, et al. (2006) Dichloroacetate causes toxic neuropathy in MELAS: a randomized, controlled clinical trial. Neurology 66:324-330.

Keller A, Nesvizhskii AI, Kolker E, and Aebersold R (2002) Empirical statistical model to estimate the accuracy of peptide identifications made by MS/MS and database search. Anal Chem 74 $5383-5392$

Kisslov I, Naamati A, Shakarchy N, and Pines O (2014) Dual-targeted proteins tend to be more evolutionarily conserved. Mol Biol Evol 31:2770-2779.

Langaee TY, Zhong G, Li W, Hamadeh I, Solayman MH, McDonough CW, Stacpoole PW, and James MO (2015) The influence of human GSTZ1 gene haplotype variations on GSTZ1 expression. Pharmacogenet Genomics 25:239-245.

Lantum HB, Baggs RB, Krenitsky DM, Board PG, and Anders MW (2002a) Immunohistochemical localization and activity of glutathione transferase zeta (GSTZ1-1) in rat tissues. Drug Metab Dispos 30:616-625.

Lantum HB, Cornejo J, Pierce RH, and Anders MW (2003) Perturbation of maleylacetoacetic acis metabolism in rats with dichloroacetic acid-induced glutathione transferase zeta deficiency. Toxicol Sci 74:192-202.

Lantum HB, Liebler DC, Board PG, and Anders MW (2002b) Alkylation and inactivation of human glutathione transferase zeta (hGSTZ1-1) by maleylacetone and fumarylacetone. Chem Res Toxicol 15:707-716.

Li W, Gu Y, James MO, Hines RN, Simpson P, Langaee T, and Stacpoole PW (2012) Prenatal and postnatal expression of glutathione transferase $\zeta 1$ in human liver and the roles of haplotype and subject age in determining activity with dichloroacetate. Drug Metab Dispos 40:232-239.

Li W, James MO, McKenzie SC, Calcutt NA, Liu C, and Stacpoole PW (2011) Mitochondrion as a novel site of dichloroacetate biotransformation by glutathione transferase zeta 1. J Pharmacol Exp Ther 336:87-94.

Lu SC (2013) Glutathione synthesis. Biochim Biophys Acta 1830:3143-3153.

Meredith MJ and Reed DJ (1982) Status of the mitochondrial pool of glutathione in the isolated hepatocyte. J Biol Chem 257:3747-3753.

Nesvizhskii AI, Keller A, Kolker E, and Aebersold R (2003) A statistical model for identifying proteins by tandem mass spectrometry. Anal Chem 75:4646-4658.

Polekhina G, Board PG, Blackburn AC, and Parker MW (2001) Crystal structure of maleylacetoacetate isomerase/glutathione transferase zeta reveals the molecular basis for its remarkable catalytic promiscuity. Biochemistry 40:1567-1576.

Raza H (2011) Dual localization of glutathione $S$-transferase in the cytosol and mitochondria: implications in oxidative stress, toxicity and disease. FEBS J 278:4243-4251.

Ribas V, García-Ruiz C, and Fernández-Checa JC (2014) Glutathione and mitochondria. Front Pharmacol 5:151.

Robin MA, Anandatheerthavarada HK, Biswas G, Sepuri NB, Gordon DM, Pain D, and Avadhan NG (2002) Bimodal targeting of microsomal CYP2E1 to mitochondria through activation of an N-terminal chimeric signal by cAMP-mediated phosphorylation. J Biol Chem 277:40583-40593.

Robin MA, Prabu SK, Raza H, Anandatheerthavarada HK, and Avadhani NG (2003) Phosphorylation enhances mitochondrial targeting of GSTA4-4 through increased affinity for binding to cytoplasmic Hsp70. J Biol Chem 278:18960-18970.
Shroads AL, Guo X, Dixit V, Liu HP, James MO, and Stacpoole PW (2008) Age-dependent kinetics and metabolism of dichloroacetate: possible relevance to toxicity. J Pharmacol Exp Ther 324:1163-1171.

Stacpoole PW (2011) The dichloroacetate dilemma: environmental hazard versus therapeutic goldmine - both or neither? Environ Health Perspect 119:155-158.

Stacpoole PW, Gilbert LR, Neiberger RE, Carney PR, Valenstein E, Theriaque DW, and Shuster JJ (2008) Evaluation of long-term treatment of children with congenital lactic acidosis with dichloroacetate. Pediatrics 121:e1223-e1228.

Stacpoole PW, Henderson GN, Yan Z, and James MO (1998) Clinical pharmacology and toxicology of dichloroacetate. Environ Health Perspect 106 (Suppl 4):989-994.

Suski JM, Lebiedzinska M, Wojtala A, Duszynski J, Giorgi C, Pinton P, and Wieckowski MR (2014) Isolation of plasma membrane-associated membranes from rat liver. Nat Protoc 9:312-322.

Tate SS and Meister A (1977) Affinity labeling of gamma-glutamyl transpeptidase and location of the gamma-glutamyl binding site on the light subunit. Proc Natl Acad Sci USA 74:931-935.

Tong Z, Board PG, and Anders MW (1998) Glutathione transferase zeta-catalyzed biotransformation of dichloroacetic acid and other $\alpha$-haloacids. Chem Res Toxicol 11:1332-1338.

Trost M, Bridon G, Desjardins M, and Thibault P (2010) Subcellular phosphoproteomics. Mass Spectrom Rev 29:962-990.

Tzeng HF, Blackburn AC, Board PG, and Anders MW (2000) Polymorphism- and speciesdependent inactivation of glutathione transferase zeta by dichloroacetate. Chem Res Toxicol 13 231-236.

Uhlén M, Fagerberg L, Hallström BM, Lindskog C, Oksvold P, Mardinoglu A, Sivertsson Å, Kampf C, Sjöstedt E, Asplund A, et al. (2015) Proteomics. Tissue-based map of the human proteome. Science 347:1260419.

Ulintz PJ, Bodenmiller B, Andrews PC, Aebersold R, and Nesvizhskii AI (2008) Investigating $\mathrm{MS}^{2} / \mathrm{MS}^{3}$ matching statistics: a model for coupling consecutive stage mass spectrometry data for increased peptide identification confidence. Mol Cell Proteomics 7:71-87.

Widdowson EM and Dickerson JW (1960) The effect of growth and function on the chemica composition of soft tissues. Biochem J 77:30-43.

Yang H, Al-Hertani W, Cyr D, Laframboise R, Parizeault G, Wang SP, Rossignol F, Berthier MT, Giguère Y, Waters PJ, et al.; Québec NTBC Study Group (2017) Hypersuccinylacetonaemia and normal liver function in maleylacetoacetate isomerase deficiency. J Med Genet 54:241-247.

Yogev $O$ and Pines $O$ (2011) Dual targeting of mitochondrial proteins: mechanism, regulation and function. Biochim Biophys Acta 1808:1012-1020.

Zhong G, Li W, Gu Y, Langaee T, Stacpoole PW, and James MO (2014) Chloride and other anions inhibit dichloroacetate-induced inactivation of human liver GSTZ1 in a haplotype-dependen manner. Chem Biol Interact 215:33-39.

Address correspondence to: Dr. Margaret O. James, Department of Medicinal Chemistry, University of Florida, 1345 Center Drive, P.O. Box 100485, Gainesville, FL 32610-0485. E-mail: mojames@ufl.edu 